\section{Kidney \\ Blood Pressure Research}

\title{
Angiopoietin-2, Renal Deterioration, Major Adverse Cardiovascular Events and All- Cause Mortality in Patients with Diabetic Nephropathy
}

\author{
Yi-Chun Tsai ${ }^{a, b, c, e} \quad$ Chee-Siong Lee ${ }^{b, d} \quad$ Yi-Wen Chiuc,e Jia-Jung Lee ${ }^{c, e} \quad$ Su-Chu Lee \\ Ya-Ling Hsu ${ }^{f}$ Mei-Chuan Kuo a,ce \\ aGraduate Institute of Clinical Medicine, College of Medicine, Kaohsiung Medical University, Kaohsiung, \\ bDivision of General Medicine, Kaohsiung Medical University Hospital, Kaohsiung, 'Division of \\ Nephrology, Kaohsiung Medical University Hospital, Kaohsiung, dDivision of Cardiology, Kaohsiung \\ Medical University Hospital, Kaohsiung, eFaculty of Renal Care, Kaohsiung Medical University, \\ Kaohsiung, fGraduate Institute of Medicine, College of Medicine, Kaohsiung Medical University, \\ Kaohsiung, Taiwan
}

\section{Key Words}

Angiopoietin-2 $\cdot$ Renal deterioration $\cdot$ MACEs $・$ Mortality $\bullet$ Diabetic nephropathy

\begin{abstract}
Background/Aims: Diabetic nephropathy is the leading cause of end-stage renal disease and accounts for 30 40\% of patients requiring maintenance dialysis, thereby increasing the burden on health insurance programs. Diabetic nephropathy is also the strongest predictor of cardiovascular morbidity and mortality. The aim of this study was to examine whether angiopoietin-2 (Angpt2), a modulator of endothelial function, affects the clinical outcomes of diabetic patients. Methods: This study enrolled 236 patients with diabetes mellitus with estimated glomerular filtration rate (eGFR) $<60 \mathrm{ml} / \mathrm{min} / 1.73 \mathrm{~m}^{2}$ from January 2006 to December 2011, who were followed until June 2017. Clinical outcomes included renal outcomes (commencing dialysis and rapid decline in renal function (eGFR decline $>3 \mathrm{ml} / \mathrm{min}$ per 1.73 $\mathrm{m}^{2} /$ year)), major adverse cardiovascular events (MACEs), and all-cause mortality. Results: Over a mean follow-up period of 3.9 2.7 years, 135 (57.2\%) patients commenced dialysis, 106 (44.9\%) had rapid decline in renal function, and 50 (21.2\%) had MACEs or died from all-causes. Log-formed Angpt2 was significantly associated with increased risks of commencing dialysis (HR: 3.91, 95\% CI: 1.56-9.76), rapid renal function decline (OR: 6.81, 95\% CI: 1.06-43.88), and MACEs or all-cause mortality (HR: 6.34, 95\% CI: 1.18-33.97) in the adjusted analysis. Patients in the highest quartile had hazard ratios of 2.90 and 3.11 for commencing dialysis and rapid
\end{abstract}




\section{Kidney Blood Pressure Research}

Tsai et al.: Angiopoietin-2 and Clinical Outcomes in Diabetic Nephropathy

renal function decline, respectively, compared to those in the lowest quartile after adjustments. Similar significant dose-response results were found in composite outcomes of either MACEs or all-cause mortality. Conclusion: Angpt2 is an independent predictor of adverse clinical outcomes in diabetic patients. Further studies are needed to identify the pathogenic role of Angpt2 in renal deterioration and cardiovascular complications of diabetes mellitus.

\section{Introduction}

Diabetes mellitus greatly affects the general population, and its prevalence is expected to increase from $2.89 \%$ in 2000 to $4.4 \%$ of the global population in 2030 [1]. Moreover, the World Health Organization (WHO) predicts that diabetes mellitus will be the seventh leading cause of death by the year 2030 [2]. Cardiovascular disease is the most common cause of death in diabetic patients. In addition, diabetic nephropathy is the leading cause of chronic kidney disease, accounting for nearly $30 \sim 50 \%$ of patients starting renal replacement therapy worldwide [3]. Furthermore, diabetic nephropathy is also the strongest predictor of morbidity and mortality in clinical diabetes mellitus. Therefore, diabetic nephropathy and its complications have an enormous impact on the affected individuals and health-care systems.

Diabetes mellitus can cause macrovascular and microvascular co-morbidities, and it can induce abnormal angiogenesis in the microvasculature and endothelial dysfunction [4]. High concentrations of angiogenic markers are easily detected in plasma and urine of diabetic patients, emphasizing the role of angiogenesis and impaired endothelium [3]. The angiopoietin (Angpt)/Tie ligand-receptor system tightly controls the endothelial phenotype during angiogenesis and vascular inflammation [5]. Diabetes mellitus increases Angpt2, which then destabilizes vascular walls by competing with Angpt1, and promotes neovascularization when is bound to vascular endothelial growth factor (VEGF) [6]. Angpt2 has been reported to be elevated in diabetic patients and to be associated with indexes of end othelial damage/dysfunction [7]. In diabetes mellitus, chronic hyperglycemia leads to the accumulation of advanced glycation end products (AGEs) and mitochondrial overproduction of reactive oxygen species (ROS). This then causes the up-regulation of Angpt2 mRNA, which has been reported to promote vascular permeability, destabilization and sprouting, further inducing microvascular and macrovascular complications in in-vitro and in-vivo studies [8-10]. However, the impact of Angpt2 on microvascular and macrovascular complications in clinical patients with diabetic nephropathy is still unclear. The aim of this study was to examine the association between serum Angpt2 and renal outcomes, including commencing dialysis and rapid renal function decline, major adverse cardiovascular events (MACEs), and all-cause mortality in patients with diabetic nephropathy.

\section{Materials and Methods}

\section{Study Participants}

This observational study was conducted at a tertiary hospital in Southern Taiwan. We enrolled 239 patients with diabetic nephropathy with estimated glomerular filtration rate $(\mathrm{eGFR})<60 \mathrm{ml} / \mathrm{min} / 1.73 \mathrm{~m}^{2}$, who were followed up at our integrated chronic kidney disease (CKD) program, from January 2006 to December 2011. Three patients who had fewer than three serum creatinine examinations during the follow-up period were excluded, and the remaining 236 patients were entered into final analysis. The study protocol was approved by the Institutional Review Board of Kaohsiung Medical University Hospital (KMUHIRB-990198). Informed consent was obtained in written form from all of the patients, and all clinical investigations were conducted according to the principles expressed in the Declaration of Helsinki. 


\section{Kidney Blood Pressure Research}

Tsai et al.: Angiopoietin-2 and Clinical Outcomes in Diabetic Nephropathy

\section{Data Collection}

Demographic and clinical data were obtained from interviews with the patients and medical records at enrollment. Diabetes was defined as a history of diabetes or the use of anti-diabetes agents. Hypertension was defined as a history of hypertension or the use of antihypertensive drugs. Cardiovascular disease was defined as a history of heart failure, acute or chronic ischemic heart disease, or myocardial infarction. Information on the use of medications including statins, $\beta$-blockers, calcium channel blockers, angiotensin converting enzyme inhibitors (ACEIs), and angiotensin II receptor blockers (ARBs) before and after enrollment was obtained from medical records. The patients were asked to fast for at least 12 hours before blood and urine sample collection for biochemistry studies and protein measurement, respectively.

\section{Quantification of Circulating Angiopoietin-2}

Plasma Angpt2 was measured in duplicate using commercial enzyme-linked immunosorbent assays (R\&D Systems Inc., Minneapolis, MN) according to the instructions of the manufacturer. The sensitivity of the Angpt2 assay was $1.20 \mathrm{pg} / \mathrm{ml}$. The interassay and intraassay coefficients of variation of Angpt2 were $1.2 \%$ and $1.8 \%$ respectively.

\section{Clinical Outcomes}

The patients were followed up at outpatient clinics at 3-month intervals to ascertain their clinical status. At least three telephone calls were made to the patients at their last known telephone number if they failed to attend follow-up visit. The renal outcomes included entering commencing dialysis (hemodialysis or peritoneal dialysis) and rapid decline in renal function. Commencing dialysis was confirmed by reviewing medical charts or catastrophic illness certificates (issued by the Bureau of National Health Insurance in Taiwan). Rapid decline in renal function was defined as the eGFR decline $>3 \mathrm{ml} / \mathrm{min} / 1.73 \mathrm{~m}^{2}$ per year (eGFR slope). The eGFR slope was calculated by using regression coefficient between eGFR and time in units of $\mathrm{ml} / \mathrm{min}$ per $1.73 \mathrm{~m}^{2}$ per year based on all eGFR values available from enrollment to the end of the observation period. At least three eGFR values were required to estimate the eGFR slope. Rapid decline in eGFR was defined as the lowest quartile (eGFR decline $>3 \mathrm{ml} / \mathrm{min} / 1.73 \mathrm{~m}^{2}$ per year, an integer near the cutoff point between the lowest two quartiles of the eGFR slope) [11]. MACEs were defined as new onset of acute coronary syndrome (myocardial infarction or unstable angina), acute hemorrhagic or ischemic stroke, or hospitalization related to acute phase of congestive heart failure. We excluded MACEs or death after commencing dialysis. The information obtained by direct contact with the patients and their families was further supplemented by reviewing medical records and the database of the National Mortality Files. Patients were censored at last contact or the end of observation in June 2017.

\section{Statistical Analysis}

The baseline characteristics of the patients were stratified by quartiles of Angpt2, with cutoff points at $1573.68,2076.54$, and $2812.26 \mathrm{pg} / \mathrm{ml}$. Continuous variables were expressed as mean $\pm \mathrm{SD}$ or median $\left(25^{\text {th }}, 75^{\text {th }}\right.$ percentile $)$, as appropriate, and categorical variables were expressed as percentages. Continuous variables with skewed distribution were log-transformed to approximate normal distribution. The significance of differences in continuous variables between groups was tested using one-way analysis of variance (ANOVA) or the Kruskal-Wallis H test, as appropriate. Differences in the distribution of categorical variables were tested using the chi-square test. Kaplan-Meier survival analysis was used to assess the predictive ability of Angpt 2 for the risk of commencing dialysis and MACEs. Cox regression models were used to examine the relationship between Angpt2 and either commencing dialysis, MACEs or all-cause mortality. Multivariate logistic regression models were used to evaluate the association between Angpt2 and rapid decline in renal function as the eGFR decline $>3 \mathrm{ml} / \mathrm{min} / 1.73 \mathrm{~m}^{2}$ per year. The multivariate models were adjusted for age, sex, smoking status, alcohol comsumption, ACEI/ARB usage, cardiovascular disease, eGFR, urine protein-creatinine ratio (PCR) with a cutoff point of $1 \mathrm{~g} / \mathrm{g}$, serum albumin, hemoglobin and cholesterol levels. Statistical analyses were conducted using SPSS version 18.0 for Windows (SPSS Inc., Chicago, Illinois). Statistical significance was set at a two-sided p-value of $<0.05$. 


\section{Kidney \\ Blood Pressure Research}

Tsai et al.: Angiopoietin-2 and Clinical Outcomes in Diabetic Nephropathy

Table 1. The clinical characteristics of study subjects stratified by angiopoietin-2 quartiles. Data are expressed as number (percentage) for categorical variables and mean \pm SD or median $\left(25^{\text {th }}, 75^{\text {th }}\right.$ percentile $)$ for continuous variables, as appropriate. Conversion factors for units: eGFR in $\mathrm{mL} / \mathrm{min} / 1.73 \mathrm{~m}^{2}$ to $\mathrm{mL} / \mathrm{s} / 1.73 \mathrm{~m}^{2}, \times 0.01667$; hemoglobin in $\mathrm{g} / \mathrm{dL}$ to $\mathrm{g} / \mathrm{L}, \times 10$; albumin in $\mathrm{g} / \mathrm{dL}$ to $\mathrm{g} / \mathrm{L}, \times 10$; calcium-phosphate product in $\mathrm{mg}^{2} / \mathrm{dL}^{2}$ to $\mathrm{mmol}^{2} / \mathrm{L}^{2}, \times 0.0806$; cholesterol in $\mathrm{mg} / \mathrm{dL}$ to $\mathrm{mmol} / \mathrm{L}, \times 0.02586$; triglyceride in $\mathrm{mg} /$ $\mathrm{dL}$ to $\mathrm{mmol} / \mathrm{L}, \times 0.01129$; uric acid in $\mathrm{mg} / \mathrm{dL}$ to $\mu \mathrm{mol} / \mathrm{L}, \times 59.48$. Abbreviations: ACEI, angiotensin converting enzyme inhibitors; ARB, angiotensin II receptor blockers; eGFR, estimated glomerular filtration rate; hsCRP, high-sensitivity C-reactive protein. ${ }^{a}$ Angiopoietin-2 quartile cut at $1573.68,2076.54$, and 2812.26pg/ml

\begin{tabular}{|c|c|c|c|c|c|c|}
\hline \multirow[b]{2}{*}{ Variables } & \multirow[b]{2}{*}{$\begin{array}{c}\text { Entire Cohort } \\
\quad \mathrm{N}=236\end{array}$} & \multirow[b]{2}{*}{$\begin{array}{l}\text { Quartile } 1 \\
\mathrm{~N}=60\end{array}$} & \multicolumn{2}{|c|}{ Angiopoietin-2a } & \multirow[b]{2}{*}{$\begin{array}{r}\text { Quartile } 4 \\
N=59\end{array}$} & \multirow[b]{2}{*}{ P-value } \\
\hline & & & $\begin{array}{l}\text { Quartile } 2 \\
\mathrm{~N}=58\end{array}$ & $\begin{array}{c}\text { Quartile } 3 \\
N=59\end{array}$ & & \\
\hline \multicolumn{7}{|l|}{ Demographics } \\
\hline Age (year) & $65.2 \pm 11.3$ & $62.9 \pm 13.5$ & $68.2 \pm 10.5$ & $66.5 \pm 8.9$ & $63.3 \pm 11.3$ & 0.030 \\
\hline Sex (male), n(\%) & $140(59.3)$ & $44(73.3)$ & $36(62.1)$ & $29(49.2)$ & $31(52.5)$ & 0.033 \\
\hline Smoke, $n(\%)$ & $63(26.8)$ & $19(31.7)$ & $10(17.2)$ & $15(25.9)$ & $19(32.2)$ & 0.228 \\
\hline Alcohol, $\mathrm{n}(\%)$ & $16(6.8)$ & $4(6.7)$ & $4(6.9)$ & $3(5.2)$ & $5(8.5)$ & 0.918 \\
\hline Cardiovascular disease, $\mathrm{n}(\%)$ & $55(23.3)$ & $19(31.7)$ & $12(20.7)$ & $12(20.3)$ & $12(20.3)$ & 0.369 \\
\hline Hypertension, $\mathrm{n}(\%)$ & $227(96.2)$ & $60(100.0)$ & $56(96.6)$ & $55(93.2)$ & $56(94.9)$ & 0.253 \\
\hline Hyperlipidemia, $n(\%)$ & $142(60.2)$ & $36(60.0)$ & $38(65.5)$ & $32(54.2)$ & $36(61.0)$ & 0.665 \\
\hline Body mass index, $\mathrm{kg} / \mathrm{m}^{2}$ & $25.4 \pm 3.8$ & $25.6 \pm 3.5$ & $25.5 \pm 4.1$ & $25.2 \pm 3.9$ & $25.2 \pm 4.0$ & 0.909 \\
\hline \multicolumn{7}{|l|}{ Medications } \\
\hline Calcium channel blocker, n (\%) & $150(63.6)$ & $33(55.0)$ & $38(65.5)$ & $35(59.3)$ & $44(74.6)$ & 0.136 \\
\hline$\beta$-blocker, n (\%) & $68(28.8)$ & $12(20.0)$ & $15(25.9)$ & $21(35.6)$ & $20(33.9)$ & 0.205 \\
\hline ACEI/ARB, n (\%) & $160(67.8)$ & $43(71.7)$ & $38(65.5)$ & $37(62.7)$ & $42(71.2)$ & 0.669 \\
\hline Statin, $n(\%)$ & $94(39.8)$ & $24(40.0)$ & $24(41.4)$ & $17(28.8)$ & $29(49.2)$ & 0.159 \\
\hline \multicolumn{7}{|l|}{ Laboratory parameters } \\
\hline $\mathrm{eGFR}\left(\mathrm{ml} / \mathrm{min} / 1.73 \mathrm{~m}^{2}\right)$ & $21.3 \pm 11.4$ & $22.0 \pm 10.6$ & $24.8 \pm 11.7$ & $19.6 \pm 11.0$ & $19.2 \pm 11.7$ & 0.029 \\
\hline Blood urea nitrogen $(\mathrm{mg} / \mathrm{dl})$ & $41.9(32.5,60.1)$ & $39.6(27.3,53.3)$ & $38.7(29.4,46.9)$ & $44.5(34.8,62.8)$ & $53.0(36.2,65.6)$ & 0.007 \\
\hline Fasting sugar $(\mathrm{g} / \mathrm{dl})$ & $117(97,149)$ & $112(97,140)$ & $118(98,149)$ & $120(97,136)$ & $120(98,161)$ & 0.587 \\
\hline Glycated hemoglobin (\%) & $6.8(6.1,8.0)$ & $6.7(6.0,7.7)$ & $6.9(6.3,7.9)$ & $6.5(6.0,7.6)$ & $7.3(6.3,8.8)$ & 0.152 \\
\hline Hemoglobin $(\mathrm{g} / \mathrm{dl})$ & $10.9 \pm 1.9$ & $11.2 \pm 2.0$ & $11.4 \pm 1.7$ & $10.7 \pm 1.9$ & $10.2 \pm 1.8$ & 0.005 \\
\hline Albumin (g/dl) & $4.0(3.8,4.2)$ & $4.1(3.8,4.3)$ & $4.0(3.8,4.2)$ & $4.0(3.7,4.2)$ & $4.0(3.6,4.2)$ & 0.456 \\
\hline Phosphate (mg/dl) & $4.2(3.7,4.9)$ & $4.1(3.7,4.8)$ & $3.9(3.6,4.4)$ & $4.3(3.8,5.0)$ & $4.3(3.9,5.3)$ & 0.017 \\
\hline Calcium (mg/dl) & $8.9 \pm 0.7$ & $9.1 \pm 0.7$ & $9.1 \pm 0.5$ & $8.8 \pm 0.7$ & $8.7 \pm 0.8$ & 0.027 \\
\hline Uric acid (mg/dl) & $7.8 \pm 1.8$ & $7.9 \pm 1.8$ & $7.7 \pm 1.7$ & $7.6 \pm 1.8$ & $8.0 \pm 1.9$ & 0.642 \\
\hline Cholesterol (mg/dl) & $183(155,214)$ & $180(155,223)$ & $181(157,212)$ & $181(151,208)$ & $192(159,229)$ & 0.680 \\
\hline Triglyceride (mg/dl) & $137(91,200)$ & $124(89,215)$ & $126(88,170)$ & $134(87,185)$ & $156(98,211)$ & 0.415 \\
\hline hsCRP (mg/L) & $2.0(0.8,4.8)$ & $1.2(0.7,3.3)$ & $2.0(0.7,3.8)$ & $2.0(0.7,4.3)$ & $2.5(0.9,6.6)$ & 0.178 \\
\hline Urine protein-creatinine ratio $>1 \mathrm{~g} / \mathrm{g}, \mathrm{n}(\%)$ & $128(59.5)$ & $30(52.6)$ & $30(58.8)$ & $29(56.9)$ & $39(69.6)$ & 0.300 \\
\hline
\end{tabular}

\section{Results}

\section{Characteristics of the Entire Cohort}

Of all 236 patients with diabetic nephropathy, the mean age was $65.2 \pm 11.3$ years and $59.3 \%$ were male. The mean eGFR of 236 patients was $21.8 \mathrm{ml} / \mathrm{min} / 1.73 \mathrm{~m}^{2}$, including 49 with eGFR $<60 \mathrm{ml} / \mathrm{min} / 1.73 \mathrm{~m}^{2}$ and $>30 \mathrm{ml} / \mathrm{min} / 1.73 \mathrm{~m}^{2}, 102$ with eGFR $<30 \mathrm{ml} / \mathrm{min} / 1.73 \mathrm{~m}^{2}$ and $>15 \mathrm{ml} / \mathrm{min} / 1.73 \mathrm{~m}^{2}$, and 85 with eGFR $<15 \mathrm{ml} / \mathrm{min} / 1.73 \mathrm{~m}^{2}$. The median of glycated hemoglobin level was $6.8 \%$ in all patients. Table 1 shows the baseline clinical characteristics stratified by quartiles of Angpt2, at 1573.68, 2076.54, and $2812.26 \mathrm{pg} / \mathrm{ml}$. Overall, $85.7 \%$ of the patients had hypertension and $23.3 \%$ had cardiovascular disease. The serum blood urea nitrogen and phosphate levels increased and eGFR, serum hemoglobin, and calcium levels decreased with increasing Angpt2 quartile. Serum Angp2 was negatively correlated with urine PCR (Spearman's r: -0.181, $\mathrm{p}=0.005$ ) and positively correlated with eGFR (Spearman's r: $0.207, p=0.002$ ) in patients with diabetic nephropathy (Fig. 1).

\section{Angiopoietin-2 and Renal Outcomes}

Over a mean follow-up period of $3.9 \pm 2.7$ years, 135 patients $(57.2 \%)$ progressed to commencing dialysis (Table 2). A stepwise increase in the proportion of those commencing dialysis from quartile 1 to quartile 4 was found ( $\mathrm{p}$ for trend=0.04). Kaplan-Meier survival curve showed a significant correlation between quartiles of Angpt2 and commencing dialysis (Fig. 2A). In univariate and multivariate Cox-regression analysis, log-formed Angpt2 was significantly associated with the increased risk of commencing dialysis (hazard ratio 


\section{Kidney \\ Blood Pressure \\ Research}

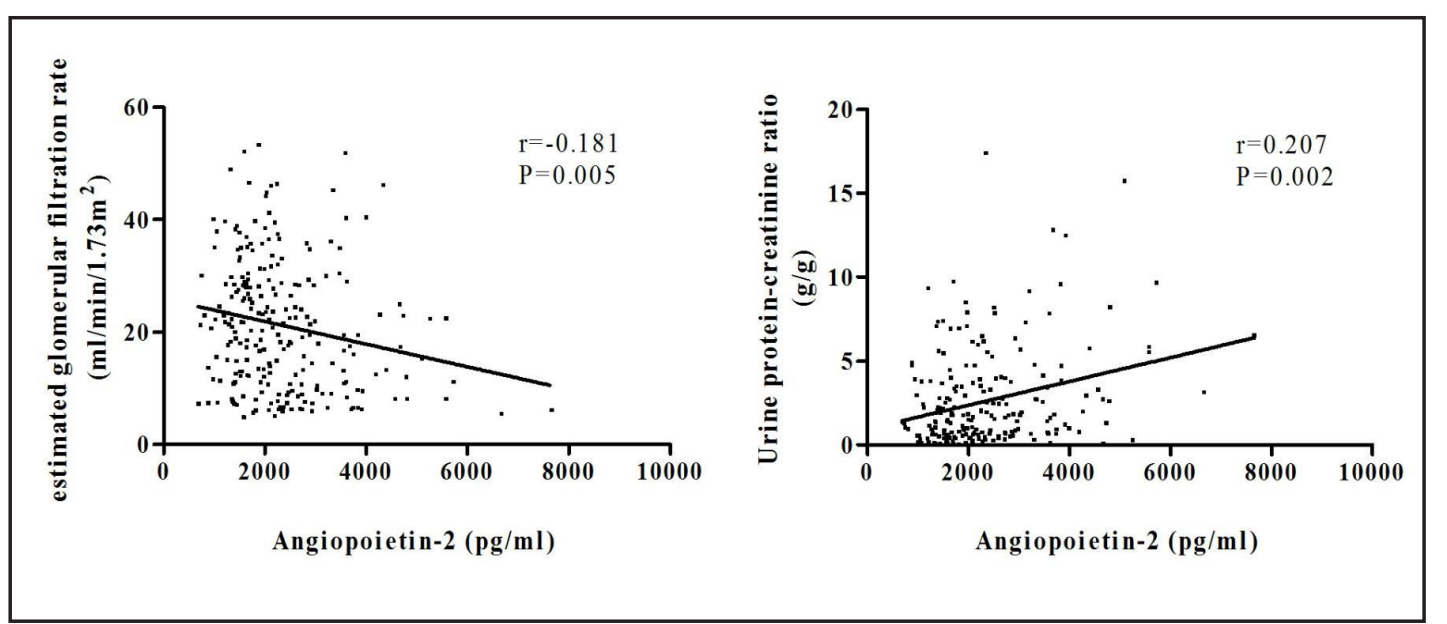

Fig. 1. Correlation between serum angiopoietin-2 level and renal function in patients with diabetic nephropathy.

Table 2. The adjusted risks for commencing dialysis and rapid progression of renal function according to Angiopoietin-2 quartiles. Abbreviations: CI, Confidence Interval; eGFR, estimated glomerular filtration rate. Adjusted model: age, sex, smoke, alcohol, cardiovascular disease, angiotensin converting enzyme inhibitors/ angiotensin II receptor blockers use, estimated glomerular filtration rate, hemoglobin, log-form cholesterol and albumin levels, and urine protein-creatinine ratio cut at 1g/g. angiopoietin-2 quartile cut at 1573.68, 2076.54 , and $2812.26 \mathrm{pg} / \mathrm{ml}$

\begin{tabular}{|c|c|c|c|c|c|c|c|}
\hline \multirow[b]{2}{*}{ Angiopoietin-2a } & \multicolumn{2}{|l|}{$\begin{array}{l}\text { Commencing } \\
\text { dialysis }\end{array}$} & \multirow[b]{2}{*}{$\mathrm{P}$-value } & \multicolumn{3}{|c|}{$\begin{array}{c}\text { eGFR decline }>3 \mathrm{~mL} / \mathrm{min} / 1.73 \mathrm{~m}^{2} \\
\text { /year }\end{array}$} & \multirow[b]{2}{*}{$\begin{array}{c}\text { P- } \\
\text { value }\end{array}$} \\
\hline & Event $(\mathrm{n} / \mathrm{N})$ & $\begin{array}{l}\text { Hazard ratio } \\
(95 \% \mathrm{Cl})\end{array}$ & & $\begin{array}{c}\text { eGFR decline }\left(\mathrm{mL} / \mathrm{min} / 1.73 \mathrm{~m}^{2}\right. \\
\text { /year) }\end{array}$ & Event $(\mathrm{n} / \mathrm{N})$ & $\begin{array}{l}\text { Odds ratio } \\
(95 \% \mathrm{Cl})\end{array}$ & \\
\hline $\begin{array}{l}\text { Log-formed } \\
\text { angiopoietin-2 }\end{array}$ & $135 / 236$ & $\begin{array}{c}3.91(1.56- \\
9.76)\end{array}$ & 0.004 & $-2.78(-5.53,-1.38)$ & $106 / 236$ & $\begin{array}{c}\text { 6.81(1.06- } \\
43.88)\end{array}$ & 0.044 \\
\hline Quartile 1 & $27 / 60$ & Reference & & $-1.74(-4.09,-0.38)$ & $20 / 60$ & Reference & \\
\hline Quartile 2 & $30 / 58$ & $\begin{array}{c}3.07(1.59- \\
5.93)\end{array}$ & 0.001 & $-3.12(-6.14,-1.71)$ & $30 / 58$ & $\begin{array}{c}5.09(1.66- \\
15.59)\end{array}$ & 0.004 \\
\hline Quartile 3 & $38 / 59$ & $\begin{array}{c}3.92(2.02- \\
7.61)\end{array}$ & $<0.001$ & $-2.74(-4.47,-1.63)$ & $24 / 59$ & $\begin{array}{c}3.41(1.13- \\
10.28)\end{array}$ & 0.029 \\
\hline Quartile 4 & $40 / 59$ & $\begin{array}{l}2.90(1.60- \\
5.27)\end{array}$ & $<0.001$ & $-3.51(-6.62,-1.51)$ & $32 / 59$ & $3.11(1.10-8.81)$ & 0.032 \\
\hline
\end{tabular}

(HR): 4.14, 95\% confidence interval (CI): 1.73-9.90, $\mathrm{p}=0.001$; HR: 3.91, 95\%CI: 1.56-9.76, $\mathrm{p}=0.004)$. The unadjusted and adjusted risks of commencing dialysis increased by 1.90 -fold (95\% CI: 1.17-3.10, p=0.01) and 2.90-fold (95\% CI: 1.60-5.27, $\mathrm{p}<0.001$ ) in the patients in quartile 4 compared to those in quartile 1 . There was a longitudinal association between commencing dialysis and a stepwise increase in Angpt2 level ( $p$ for trend $=0.01$ ).

One hundred and six patients (44.9\%) had rapid renal function decline as eGFR decline $>3 \mathrm{~mL} / \mathrm{min} / 1.73 \mathrm{~m}^{2}$ per year. There was a significant difference in the slope of eGFR decline per year among the Angpt2 quartiles ( $p=0.007)$, and the patients in Angpt2 quartile 4 had the greatest decline in eGFR. Log-formed Angpt 2 was significantly associated with an increased risk of the decline in eGFR $>3 \mathrm{~mL} / \mathrm{min} / 1.73 \mathrm{~m}^{2}$ per year (odds ratio (OR): $4.78,95 \% \mathrm{CI}$ : 1.21-18.93, $\mathrm{p}=0.026$; OR: 6.81, 95\% CI: 1.06-43.88, $\mathrm{p}=0.044$ ). The unadjusted and adjusted ORs for rapid decline in renal function were 2.37 (95\% CI: 1.13-4.97) and 3.11(95\% CI: 1.108.81) for of the patients in quartile 4 compared to those in quartile 1 (Table 2).

We performed subgroup analysis (Table 3), and found a consistent association between log-formed Angpt2 and commencing dialysis in the patients with glycated hemoglobin level $<7.5 \%$ (HR for every log Angpt2: 3.38, 95\%CI: 1.20-9.52), in those with glycated hemoglobin level $\geq 7.5 \%$ (HR for every log Angpt2: 5.95, 95\%CI: 1.03-34.38), and in those with urine PCR of 1g/g or more (HR for every log Angpt2: 3.79, 95\%CI: 1.52-9.44), after adjusting for age, sex, cardiovascular disease and baseline eGFR. In the patients with urine PCR of $1 \mathrm{~g} / \mathrm{g}$ or more, high levels of Angpt2 were correlated with high risk for commencing dialysis independently of glycated hemoglobin. 


\section{Kidney Blood Pressure Research}

\section{Angiopoietin-2, MACEs and} All-cause Mortality

Of all patients, 50 patients (21.2\%) had MACEs or died from all-causes (Table 4) before commencing dialysis. Fortysix had MACEs, 26 died, and 14 had both MACEs and then died during the follow-up period. Of the patients who died, sepsis accounted for $27 \%$, MACEs for $23 \%$, malignancy for $12 \%$, and the rest were a mixture of refusing dialysis and other causes. The MACEs included 13 cases of acute myocardial infarction, nine with acute hemorrhagic or ischemic stroke, 23 with hospitalizations due to congestive heart failure, and one with aortic dissection. There were no significant differences in the causes of death and cardiovascular events between the four groups.

Log-formed Angpt2 was significantly associated with composite outcomes of either MACEs or all-cause mortality (HR: 6.34, 95\% CI: 1.18-33.97, $\mathrm{p}=0.031$ ) and MACEs alone (HR: 8.11, 95\% CI: 1.158-41.52, $\mathrm{p}=0.012$ ) in Cox proportional and multivariate analysis (Table 4). The adjusted HR of composite outcomes of either MACEs or all-cause mortality was 2.69 (95\% CI: 1.05-6.90) for the patients in quartile 4 compared to those in quartile 1 . The adjusted

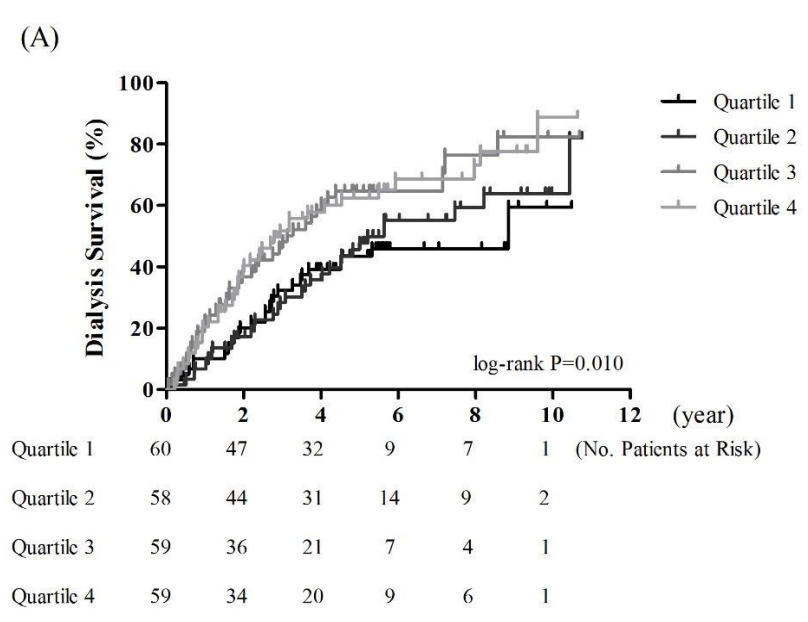

(B)

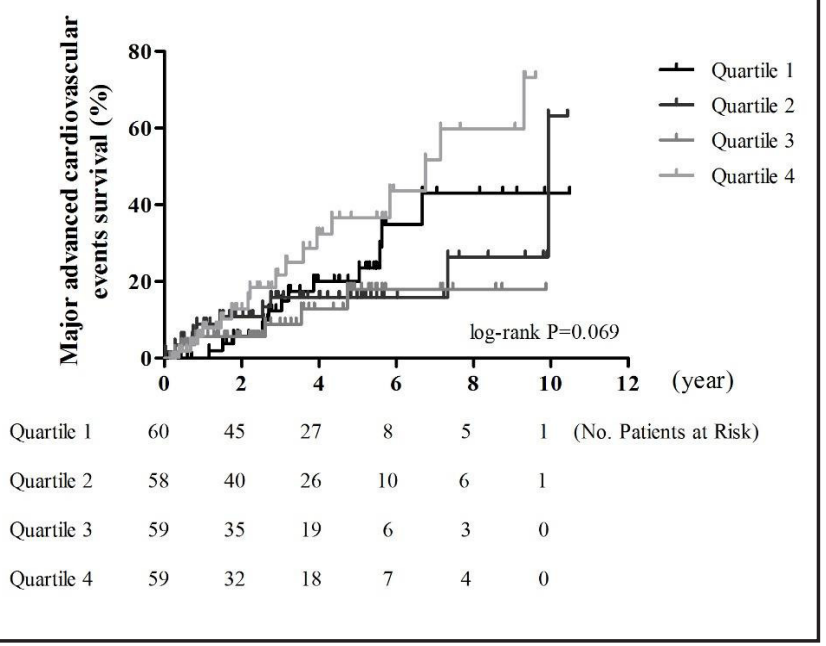

Fig. 2. Kaplan-Meier survival curve for commencing dialysis (A) and major advanced cardiovascular events (MACEs) (B) in patients with diabetic nephropathy according to angiopoietin-2 quartiles.

Table 3. The adjusted risks for commencing dialysis according to Angiopoietin-2 in patients stratified by glycated hemoglobin and urine protein-creatinine ratio. Abbreviations: CI, Confidence Interval; eGFR, estimated glomerular filtration rate, HbA1C, glycated hemoglobin. Adjusted model: age, sex, cardiovascular disease, estimated glomerular filtration rate

\begin{tabular}{|c|c|c|c|}
\hline \multicolumn{4}{|c|}{ Commencing dialysis } \\
\hline Log-formed Angiopoietin-2a & Event $(\mathrm{n} / \mathrm{N})$ & Hazard ratio $(95 \% \mathrm{Cl})$ & P-value \\
\hline $\mathrm{HbA} 1 \mathrm{C} \geqq 7.5 \%$ & $41(72)$ & $5.95(1.03-34.39)$ & 0.046 \\
\hline $\mathrm{HbA} 1 \mathrm{C}<7.5 \%$ & $89(157)$ & $3.38(1.20-9.52)$ & 0.021 \\
\hline $\mathrm{UPCR} \geqq 1 \mathrm{~g} / \mathrm{g}$ & $104(128)$ & $3.79(1.52-9.44)$ & 0.004 \\
\hline UPCR $<1 \mathrm{~g} / \mathrm{g}$ & $19(87)$ & $1.79(0.18-17.33)$ & 0.618 \\
\hline $\mathrm{HbA} 1 \mathrm{C} \geqq 7.5 \% \& \mathrm{UPCR} \geqq 1 \mathrm{~g} / \mathrm{g}$ & $31(41)$ & $8.40(1.16-60.65)$ & 0.035 \\
\hline $\mathrm{HbA} 1 \mathrm{C}<7.5 \%$ \& UPCR $\geqq 1 \mathrm{~g} / \mathrm{g}$ & $70(84)$ & $3.17(1.02-9.86)$ & 0.046 \\
\hline $\mathrm{HbA} 1 \mathrm{C} \geqq 7.5 \% \& \mathrm{UPCR}<1 \mathrm{~g} / \mathrm{g}$ & $6(23)$ & $1.78(0.01-438.41)$ & 0.838 \\
\hline $\mathrm{HbA} 1 \mathrm{C}<7.5 \%$ \& UPCR $<1 \mathrm{~g} / \mathrm{g}$ & $13(62)$ & $1.56(0.09-27.26)$ & 0.763 \\
\hline
\end{tabular}




\section{Kidney Blood Pressure Research}

Tsai et al.: Angiopoietin-2 and Clinical Outcomes in Diabetic Nephropathy

Table 4. The adjusted risks for major advanced cardiac events (MACEs) and all-cause mortality according to Angiopoietin-2 quartiles. Abbreviations: CI, Confidence Interval; eGFR, estimated glomerular filtration rate. Adjusted model: age, sex, smoke, alcohol, cardiovascular disease, angiotensin converting enzyme inhibitors/ angiotensin II receptor blockers use, estimated glomerular filtration rate, hemoglobin, log-form cholesterol and albumin levels, and urine protein-creatinine ratio cut at $1 \mathrm{~g} / \mathrm{g}$. ${ }^{a}$ Angiopoietin-2 quartile cut at 1573.68, 2076.54 , and $2812.26 \mathrm{pg} / \mathrm{ml}$

\begin{tabular}{|c|c|c|c|c|c|c|c|c|c|}
\hline & MACEs+ all-cause mortality & & & MACEs & & & 11-cause mortali & & \\
\hline Angiopoietin-2a & $\begin{array}{l}\text { Event } \\
(\mathrm{n} / \mathrm{N})\end{array}$ & $\begin{array}{l}\text { Hazard ratio } \\
(95 \% \mathrm{Cl})\end{array}$ & P-value & $\operatorname{Event}(n / N)$ & $\begin{array}{l}\text { Hazard ratio } \\
(95 \% \mathrm{Cl})\end{array}$ & P-value & Event $(\mathrm{n} / \mathrm{N})$ & $\begin{array}{l}\text { Hazard ratio } \\
(95 \% \mathrm{Cl})\end{array}$ & P-value \\
\hline Log-formed angiopoietin-2 & $50 / 236$ & $6.34(1.18-33.97)$ & 0.031 & $46 / 236$ & $8.11(1.58-41.52)$ & 0.012 & $26 / 236$ & $2.37(0.24-23.53)$ & 0.461 \\
\hline Quartile 1 & $12 / 60$ & Reference & & $13 / 60$ & Reference & & $6 / 60$ & Reference & \\
\hline Quartile 2 & $14 / 58$ & $1.29(0.52-5.18)$ & 0.582 & $10 / 58$ & $0.95(0.38-2.39)$ & 0.915 & $8 / 58$ & $1.04(0.29-3.75)$ & 0.956 \\
\hline Quartile 3 & $10 / 59$ & $1.03(0.34-3.10)$ & 0.956 & $6 / 59$ & $0.54(0.14-2.05)$ & 0.366 & $7 / 59$ & $1.37(0.35-5.36)$ & 0.653 \\
\hline Quartile 4 & $14 / 59$ & $2.69(1.05-6.90)$ & 0.039 & $17 / 59$ & $2.84(1.20-6.70)$ & 0.017 & $5 / 59$ & $1.40(0.37-5.32)$ & 0.622 \\
\hline
\end{tabular}

HR of MACEs was 2.84 (95\% CI: 1.20-6.70) for the patients in quartile 4 compared to those in quartile 1. There was a longitudinal association between stepwise increases in Angpt2 levels and MACEs ( $\mathrm{p}$ for trend=0.024). Although no significant result was found in Kaplan-Meier survival analysis, the patients in Angpt2 quartile 4 had higher risk for having MACEs than those in the other quartiles (Fig. 2B). There was no significant correlation between Angpt2 level and all-cause mortality in patients with diabetic nephropathy.

\section{Discussion}

In this study, high serum Angpt2 levels were associated with the increased risk of poor renal outcomes, including commencing dialysis and rapid decline in renal function in patients with diabetic nephropathy over a follow-up period of nearly 4 years. A significant relationship between serum Angpt2 level and MACEs was also noted in patients with diabetic nephropathy after adjustments for well-known risk factors. Taken together, serum Angpt2 appears to be a potential predictor of adverse clinical outcomes in patients with diabetic nephropathy.

Over-expression of Angpt2 inhibits binding of Angpt1 to Tie-2 receptor, which contributes to the development of diabetic nephropathy. Abnormal alterations in Angpt1/ Angpt2 cause excess angiogenesis and inflammation, which play a crucial role in the pathophysiologic mechanism of diabetic nephropathy [12]. Increasing evidence suggests that the upregulation of Angpt2 is harmful for kidney physiology and function. Podocyte-directed Angpt2 transgenic over-expression has been reported to cause glomerular endothelial cell apoptosis, increase albuminuria, and down-regulate the expression of nephrin [13]. In addition, the increased expression of Angpt2 may destabilize glomerular endothelial cells and affect podocytes in the paracrine fashion, inducing the decay of glomerular filtration barrier function [14]. Chen et al. found that serum and urinary Angpt2 levels were increased in normoalbuminuric patients with diabetes mellitus, suggesting that Angpt2 may be an earlier measurable indicator of tubular impairment before the onset of clinical symptoms or signs, such as microalbuminuria [15]. Consistent with their report [15], serum Angpt2 increased stepwisely with urine PCR, and this was inreversely correlated with eGFR in our patients with diabetic nephropathy. Our previous study suggested that serum Angpt2 level was an independent risk factor for adverse renal outcomes in patients with CKD stages 3-5 [16]. However, whether serum Angpt2 can predict rapid deterioration in renal function in patients with clinical diabetes mellitus has not been well-explored. We followed diabetic patients over a 4-year period, and found that those with high levels of serum Angpt2 were more likely to commence dialysis and have rapid renal function decline; therefore, Angpt2 may be a reliable marker tp detect deterioration in renal function in clinical practice.

Dysfunction in angiogenesis and endothelium has been reported to be a common cause of diabetic vascular complications [17], and Angpt2 involved in various vascular diseases such as arteriosclerosis and hypertension [18-20]. In addition, serum Angpt2 levels has been 


\section{Kidney Blood Pressure Research}

correlated with subclinical cardiovascular diseases such as fractional shortening, number of carotid plaques [21] and carotid intima media thickness [22]. In our previous reports, we found that CKD patients with high serum Angpt2 levels were more likely to have high brachialankle pulse wave velocity, high left ventricular mass index and left ventricular hypertrophy [23]. Serum Angpt2 was associated with abnormal cardiovascular structure, and increased cardiovascular burden. Furthermore, serum Angpt2 has been considered as a predictor of allcause mortality and cardiovascular mortality in the general population [24] and in patients with CKD [25]. Nevertheless, the information between serum Angpt2 and MACEs and allcause mortality is limited in patients with diabetes mellitus. Hyperglycemia has been shown to cause an increase in Angpt2 expression, which can then induce myocardial apoptosis, increase infraction size, impair cardiac angiogenesis and exacerbate cardiac fibrosis in type 1 and type 2 diabetic mice [26, 27]. In the present study, Angpt2 was independently associated with the increased risk for composite outcomes of either MACEs or all-cause mortality, and MACEs alone. The relatively small number of study patients and relatively short observation period may explain the lack of no significant correlation between serum Angpt2 and allcause mortality. We suggest that serum Angpt2 can potentially be used to predict MACEs in patients with diabetic nephropathy who have high risks of macrovascular complications.

Strict glycemic control has been shown to be very beneficial in preventing the development of microvascular and macrovascular complications in diabetes mellitus [28, 29]. However, some studies have reported that intensive glycemic control may not be enough to stop rapid deterioration in renal function in late CKD [30]. Our diabetic patients had good control of glucose that glycated hemoglobin level was under the recommendation value by American Diabetes Association (ADA) [31]. Therefore, we performed subgroup analysis to examine the effect of glycated hemoglobin on the association between serum Angpt 2 and adverse renal outcomes in patients with diabetes mellitus. The results showed a consistent correlation between serum Angpt 2 and commencing dialysis in diabetic patients with glycated hemoglobin level of $<7.5 \%$ or $\geqq 7.5 \%$. Therefore, Angpt 2 may have a stronger influence on adverse renal outcomes than glycated hemoglobin level in patients with diabetes mellitus. Additionally, because of the large effect of urine PCR on renal progression, we stratified diabetic patients according to urine PCR of $1 \mathrm{~g} / \mathrm{g}$, and the association between serum Angpt 2 and commencing dialysis only existed in those with urine PCR $\geqq 1 \mathrm{~g} / \mathrm{g}$, but not in those with urine PCR $<1 \mathrm{~g} / \mathrm{g}$. In further analysis, we found that serum Angpt2 was associated with increased risk for commencing dialysis in diabetic patients with urine $\mathrm{PCR} \geqq 1 \mathrm{~g} / \mathrm{g}$, independently of glycated hemoglobin level. Therefore, serum Angpt 2 appears to be an independent predictor of adverse renal outcomes in diabetic patients, especially in those with urine $P C R \geqq 1 \mathrm{~g} / \mathrm{g}$.

There are several limitations to this study. First, it is uncertainty whether circulating Angpt2 has a biologically active effect in diabetic patients, and the biological implication of Angpt2 changes in the range observed in our patients is still unclear. Second, Angpt2 was measured once at enrollment, and the effect of variation in Angpt2 levels over time may have been underestimated. Third, the relatively small number of study patients may have limited the statistical analysis of all-cause mortality. However, our results are sufficient to provide strong evidence of the association between Angpt2 and adverse clinical outcomes in patients with diabetic nephropathy. Finally, we did not measure circulating Angpt1 or VEGF levels in this study. From a pathophysiological perspective, it may have been helpful if we had further clarified the potential effects of these markers.

\section{Conclusion}

This study demonstrated that elevated levels of serum Angpt2 were associated with high risks of commencing dialysis, rapid renal function decline and MACEs in patients with diabetic nephropathy. Future studies are necessary to evaluate the pathogenic role of 


\section{Kidney \\ Blood Pressure Research}

Tsai et al.: Angiopoietin-2 and Clinical Outcomes in Diabetic Nephropathy

Angpt2 in microvascular and macrovascular complications, and moreover, to investigate the potential benefits in clinical outcomes that may be achieved by targeting Angpt2 in patients with diabetes mellitus.

\section{Acknowledgements}

Dr. Tsai's research was supported by a grant from Ministry of Science and Technology (MOST 105-2314-B-037-022) and Kaohsiung Medical University Hospital (KMUH1055R22).

\section{Disclosure Statement}

The authors declare no conflicts of interest.

\section{References}

1 Wild S, Roglic G, Green A, Sicree R, King H: Global prevalence of diabetes: Estimates for the year 2000 and projections for 2030. Diabetes Care 2004;27:1047-1053.

2 World Health Organization: Global Status Report on Noncommunicable Diseases 2010, World Health Organization, Geneva, Switzerland, 2011.

$>3$ White SL, Cass A, Atkins RC, Chadban SJ: Chronic kidney disease in the general population. Adv Chronic Kidney Dis 2005;12:5-13.

4 Shi Y, Vanhoutte PM: Macro- and microvascular endothelial dysfunction in diabetes. J Diabetes 2017;9:434449.

5 Brindle NP, Saharinen P, Alitalo K: Signaling and functions of angiopoietin-1 in vascular protection. Circ Res 2006;98:1014-1023.

-6 Fiedler U, Augustin HG: Angiopoietins: a link between angiogenesis and inflammation. Trends Immunol 2006;27:552-558.

-7 Lim HS, Blann AD, Chong AY, Freestone B, Lip GY: Plasma vascular endothelial growth factor, angiopoietin-1, and angiopoietin-2 in diabetes: implications for cardiovascular risk and effects of multifactorial intervention. Diabetes Care 2004;27:2918-2924.

8 Giacco F, Brownlee M: Oxidative stress and diabetic complications. Circ Res 2010;107:1058-1070.

-9 Okamoto T, Yamagishi S, Inagaki Y, Amano S, Koga K, Abe R, Takeuchi M, Ohno S, Yoshimura A, Makita Z: Angiogenesis induced by advanced glycation end products and its prevention by cerivastatin. FASEB J 2002;16:1928-1930.

10 Lobov IB, Brooks PC, Lang RA: Angiopoietin-2 displays VEGF-dependent modulation of capillary structure and endothelial cell survival in vivo. Proc Natl Acad Sci USA 2002;99:11205-11210.

11 Chen SC, Su HM, Hung CC, Chang JM, Liu WC, Tsai JC, Lin MY, Hwang SJ, Chen HC: Echocardiographic parameters are independently associated with rate of renal function decline and progression to dialysis in patients with chronic kidney disease. Clin J Am Soc Nephrol 2011;6:2750-2758.

12 Nazir N, Siddiqui K, Al-Qasim S, Al-Naqeb D: Meta-analysis of diabetic nephropathy associated genetic variants in inflammation and angiogenesis involved in different biochemical pathways. BMC Med Genet 2014;15:103.

13 Davis B, Dei Cas A, Long DA, White KE, Hayward A, Ku CH, Woolf AS, Bilous R, Viberti G, Gnudi L: Podocytespecific expression of angiopoietin-2 causes proteinuria and apoptosis of glomerular endothelia. J Am Soc Nephrol 2007;18:2320-2329.

14 Fu J, Lee K, Chuang PY, Liu Z, He JC: Glomerular endothelial cell injury and cross talk in diabetic kidney disease. Am J Physiol Renal Physiol 2015;308:287-297.

15 Chen S, Li H, Zhang C, Li Z, Wang Q, Guo J, Luo C, Wang Y: Urinary angiopoietin-2 is associated with albuminuria in patients with type2 diabetes mellitus. Int J Endocrinol 2015;2015:163120. 


\section{Kidney \\ Blood Pressure Research}

Tsai et al.: Angiopoietin-2 and Clinical Outcomes in Diabetic Nephropathy

16 Tsai YC, Chiu YW, Tsai JC, Kuo HT, Lee SC, Hung CC, Lin MY, Hwang SJ, Kuo MC, Chen HC: Association of angiopoietin-2 with renal outcome in chronic kidney disease. PLoS One 2014;9:e108862.

17 Tremolada G, Lattanzio R, Mazzolari G, Zerbini G: The therapeutic potential of VEGF inhibition in diabetic microvascular complications. Am J Cardiovasc Drugs 2007;7:393-398.

18 Marti HH, Risau W: Angiogenesis in ischemic disease. Thromb Haemost 1999;82:44-52.

19 Nadar SK, Blann A, Beevers DG, Lip GY: Abnormal angiopoietins 1\&2, angiopoietin receptor Tie-2 and vascular endothelial growth factor levels in hypertension: relationship to target organ damage [a sub-study of the Anglo-Scandinavian Cardiac Outcomes Trial (ASCOT)]. J Intern Med 2005;258:336-343.

-20 Rasul S, Reiter MH, Ilhan A, Lampichler K, Wagner L, Kautzky-Willer A: Circulating angiopoietin-2 and soluble Tie-2 in type 2 diabetes mellitus: a cross-sectional study. Cardiovasc Diabetol 2011;10:55.

-21 Lorbeer R, Baumeister SE, Dörr M, Felix SB, Nauck M, Grotevendt A, Markus MR, von Sarnowski B, Völzke H, Vasan RS, Wallaschofski H, Lieb W: Angiopoietin-2, its soluble receptor Tie-2 and subclinical cardiovascular disease in a population-based sample. Heart 2015;101:178-184.

-22 Shroff RC, Price KL, Kolatsi-Joannou M, Todd AF, Wells D, Deanfield J, Johnson RJ, Rees L, Woolf AS, Long DA: Circulating angiopoietin-2 is a marker for early cardiovascular disease in children on chronic dialysis. PLoS One 2013;8:e56273.

23 Tsai YC, Lee CS, Chiu YW, Kuo HT, Lee SC, Hwang SJ, Kuo MC, Chen HC: Angiopoietin-2, angiopoietin-1 and subclinical cardiovascular disease in chronic kidney disease. Sci Rep 2016;6:39400.

-24 Lorbeer R, Baumeister SE, Dörr M, Nauck M, Grotevendt A, Völzke H, Vasan RS, Wallaschofski H, Lieb W.: Circulating angiopoietin-2, its soluble receptor Tie-2, and mortality in the general population. Eur J Heart Fail 2013;15:1327-1334.

25 Tsai YC, Lee CS, Chiu YW, Kuo HT, Lee SC, Hwang SJ, Kuo MC, Chen HC. Angiopoietin-2 as a prognostic biomarker of major adverse cardiovascular events and all-cause mortality in chronic kidney disease. PLoS One 2015; 10:e0135181.

-26 Tuo QH, Zeng H, Stinnett A, Yu H, Aschner JL, Liao DF, Chen JX: Critical role of angiopoietins/Tie-2 in hyperglycemic exacerbation of myocardial infarction and impaired angiogenesis. Am J Physiol Heart Circ Physiol 2008;294:2547-2557.

27 Chen JX, Zeng H, Reese J, Aschner JL, Meyrick B: Overexpression of angiopoietin-2 impairs myocardial angiogenesis and exacerbates cardiac fibrosis in the diabetic $\mathrm{db} / \mathrm{db}$ mouse model. Am J Physiol Heart Circ Physiol 2012;302:1003-1012.

28 Diabetes Control and Complications Trial Research Group: The effect of intensive treatment of diabetes on the development and progression of long-term complications in insulin-dependent diabetes mellitus. $\mathrm{N}$ Engl J Med 1993;329:977-986.

29 UK Prospective Diabetes Study (UKPDS) Group: Intensive blood-glucose control with sulphonylureas or insulin compared with conventional treatment and risk of complications in patients with type 2 diabetes (UKPDS 33). Lancet 1998;352:837-853.

30 Shurraw S, Hemmelgarn B, Lin M, Majumdar SR, Klarenbach S, Manns B, Bello A, James M, Turin TC, Tonelli M, Alberta Kidney Disease Network: Association between glycemic control and adverse outcomes in people with diabetes mellitus and chronic kidney disease: a population-based cohort study. Arch Intern Med 2011;171:1920-1927.

-31 American Diabetes Association. Pharmacologic Approaches to Glycemic Treatment: Standards of Medical Care in Diabetes-2018. Diabetes Care 2018;41:S73-S85. 